ORIGINAL RESEARCH

\title{
Oximetry Fails to Predict Acute Mountain Sickness or Summit Success During a Rapid Ascent to 5640 Meters
}

\author{
Dale R. Wagner, PhD; Jonathan R. Knott, MS; Jack P. Fry, BS \\ From the Human Movement Science Program (Dr Wagner, Mr Knott, and Mr Fry), HPER Department, Utah State University, Logan, UT.
}

\begin{abstract}
Objective.-The purpose of this study was to determine whether arterial oxygen saturation $\left(\mathrm{SpO}_{2}\right)$ and heart rate (HR), as measured by a finger pulse oximeter on rapid arrival to $4260 \mathrm{~m}$, could be predictive of acute mountain sickness (AMS) or summit success on a climb to $5640 \mathrm{~m}$.

Methods.-Climbers ( $35.0 \pm 10.1$ years; 51 men, 5 women) were transported from $2650 \mathrm{~m}$ to the Piedra Grande hut at $4260 \mathrm{~m}$ on Pico de Orizaba within 2 hours. After a median time of 10 hours at the hut, they climbed toward the summit $(5640 \mathrm{~m})$ and returned, with a median trip time of 14 hours. The Lake Louise Self-Assessment Scale (LLSS) for AMS, HR, and $\mathrm{SpO}_{2}$ were collected on arrival at the hut and repeated immediately before and after the climbers' summit attempts.

Results.-Average $\mathrm{SpO}_{2}$ for all participants at $4260 \mathrm{~m}$ before their departure for the summit was $84.4 \% \pm 3.7 \%$. Thirty-seven of the 56 participants reached the summit, and $59 \%$ of all climbers met the criteria for AMS during the ascent. The $\mathrm{SpO}_{2}$ was not significantly different between those who experienced AMS and those who did not $(P=.82)$; neither was there a difference in $\mathrm{SpO}_{2}$ between summiteers and nonsummiteers $(P=.44)$. Climbers' HR just before the summit attempt was not related to AMS but was significantly lower for summiteers vs nonsummiteers $(P=.04)$.

Conclusions.- The $\mathrm{SpO}_{2}$ does not appear to be predictive of AMS or summit success during rapid ascents.
\end{abstract}

Key words: arterial oxygen saturation, heart rate, AMS, hypoxia, high altitude, mountaineering

\section{Introduction}

Acute mountain sickness (AMS) is a syndrome that often presents itself above $2500 \mathrm{~m}$ and is characterized by a headache with at least one other symptom such as gastrointestinal upset, fatigue, dizziness, or sleep disturbance. ${ }^{1}$ For mountaineers, AMS can cause substantial discomfort and disrupt summit attempts. Furthermore, it is thought to be a precursor to the more serious condition of high altitude cerebral edema. ${ }^{2}$

Several scales have been developed and used to make assessments of AMS, most notably the Environmental Symptoms Questionnaire, ${ }^{3}$ the Lake Louise Self-Assessment Scale (LLSS), ${ }^{1}$ and a visual analog scale (VAS). ${ }^{4}$ However, all of these scales are subjective and rely on

Presented in poster format at the 8th World Congress of High Altitude Medicine and Physiology, Arequipa, Peru, August 2010.

Disclaimer: The authors have no conflict of interest to report.

Corresponding author: Dale R. Wagner, PhD, USU HPER Department, Utah State University, 7000 Old Main Hill, Logan, UT 843227000 (e-mail: dale.wagner@usu.edu). the climber or patient making an accurate and truthful self-evaluation of his or her symptoms. Thus, an objective and quantifiable measurement to predict impending AMS during an expedition would be extremely valuable to the safety and success of climbers.

Lightweight, portable, finger pulse oximeters allow for a safe, easy, and noninvasive measurement of arterial oxygen saturation $\left(\mathrm{SpO}_{2}\right)$. Pulse oximetry might provide the quantifiable objectivity that is lacking in AMS assessment. It is well known that ascending to high altitude leads to both a decrease in $\mathrm{Spo}_{2}$ and an increased risk of AMS. However, it is unclear whether an increase in AMS symptoms is a secondary response to the reduced $\mathrm{SpO}_{2}$ or whether these 2 hypoxic events are independent of one another. There appears to be no association between $\mathrm{SpO}_{2}$ and AMS when the pulse oximetry measurement is taken soon after arriving at high altitude., However, several researchers have suggested that low $\mathrm{SpO}_{2}$ might be a predictor of impending AMS if the climber remains at altitude or continues a prolonged ascent. $^{7,8}$ 
Could finger pulse oximetry also be used to predict summit success or failure for an ascent of a high altitude peak? Because $\mathrm{Spo}_{2}$ influences oxygen delivery and it is reduced with increasing hypoxia, it seems logical that a low $\mathrm{SpO}_{2}$ at the beginning of a high altitude ascent might be predictive of failure. However, there is a lack of published research examining the relationship between $\mathrm{SpO}_{2}$ and summit success, particularly for rapid ascents. Thus, the question of whether or not a measure of $\mathrm{SpO}_{2}$ could be used to predict 1) AMS or 2) summit success for a rapid ascent to more than $5000 \mathrm{~m}$ has been raised and was the purpose of our study.

\section{Methods}

\section{SETTING AND PARTICIPANTS}

The study was conducted from the Piedra Grande climber's hut $(4260 \mathrm{~m})$ on the north side of Pico de Orizaba $(5640 \mathrm{~m})$, the highest point in Mexico. Every climber arriving at the hut intending to make a summit attempt was informed about the study and invited to participate. A document describing the purpose, procedures, risks, and benefits of participation, as well as confidentiality and voluntary participation statements, was presented in both English and Spanish. Potential participants were encouraged to ask questions about the study before agreeing to participate, and voluntary informed consent was obtained. Climbers who did not understand either English or Spanish were excluded from the study. The institutional review board of Utah State University approved this study.

Data collection occurred inside the hut and spanned 8 consecutive days. As a popular climbing destination with easy access, this location allowed for a large number of participants to take part in the study. This site was also chosen for its optimal altitude for $\mathrm{Spo}_{2}$ measurements for the prediction of AMS, ${ }^{9}$ as well as to make comparisons with other research conducted at a similar altitude. ${ }^{8}$ In addition, ascents of Pico de Orizaba are typically completed in a rapid fashion, with climbers arriving at the hut at midday, staying for about half the day, and then attempting the summit in one long effort from the hut. This rapid ascent profile created a short duration between testing and retesting, providing the opportunity to test our research questions.

\section{PROCEDURES}

Climbers traveled by truck from the village of Tlachichuca $(2650 \mathrm{~m})$ to the Piedra Grande hut. As a result of this mode of travel they rapidly gained $1610 \mathrm{~m}$ of elevation within about 2 hours. The date and time of each participant's arrival to the hut was noted, and the initial data collection occurred within 30 minutes of their arrival at the hut.

The initial data collection included the following selfreported information: age, gender, height, weight, altitude of residence, history of altitude illness, number of ascents above $3000 \mathrm{~m}$ in the 10 days before this ascent, time above $3000 \mathrm{~m}$ in the 10 days before this ascent, highest altitude achieved, and hours per week of training in the month before this ascent. The LLSS for $\mathrm{AMS}^{1}$ was administered by paper and pencil, and both English and Spanish versions were available. This self-assessment scale involves ranking AMS symptoms on a scale of 0 ("none at all") to 3 ("severe or incapacitating"). The criteria for AMS are a headache, plus at least one other symptom, and a total score of 3 or more. This is the recommended assessment method and criteria for evaluating AMS. ${ }^{10}$ Additionally, pulse oximetry measurements were taken to obtain $\mathrm{Spo}_{2}$ and heart rate (HR) data. A pulse oximeter (Onyx 9500 SportStat; Nonin Medical Inc, Plymouth, MN) was placed on the right index finger while the climber was seated, and the $\mathrm{Spo}_{2}$ and HR values remained stable for 1 minute before being recorded. According to the manufacturer, this oximeter is accurate to \pm 2 digits for $\mathrm{SpO}_{2}$ of $70 \%$ to $100 \%$. After this initial data collection, the climbers stayed in or near the hut until their summit attempt.

Immediately before the climbers departed for their summit attempts, the finger pulse oximetry measurement and the LLSS questionnaire were repeated. The time of the climbers' departure was recorded. Within minutes of their return to the hut from their summit attempts the assessments were repeated, and their time spent climbing was recorded. This postascent administration of the LLSS for AMS was phrased so as to describe the climber's perceived symptoms of sickness throughout the duration of their ascent above the hut $(4260 \mathrm{~m})$. Climbers were also asked whether they had reached the summit, and whether they had used acetazolamide or dexamethasone. The climbers who did not reach the summit were asked to give a reason why. Possible reasons included AMS symptoms, weather, fatigue, partner failure, or other.

\section{STATISTICAL ANALYSES}

The total time each climber spent at or above the hut was calculated. The LLSS was scored, and a diagnosis of AMS ("yes" or "no") was made for all 3 data collection periods: 1) arrival at $4260 \mathrm{~m}, 2$ ) immediately before departure for the summit attempt, and 3) immediately on return from the summit attempt. A Pearson productmoment correlation was run between $\mathrm{SpO}_{2}, \mathrm{HR}$, and the 
LLSS score. Independent Student's $t$ tests were done with $\mathrm{SpO}_{2}$ and $\mathrm{HR}$ as the dependent variables to determine whether there was a significant mean difference between climbers who reported experiencing AMS and those who did not, as well as to test mean differences between summiteers and nonsummiteers. Additionally, the change in $\mathrm{SpO}_{2}$ and $\mathrm{HR}$ with time (arrival at hut, departure for summit attempt, and return from attempt) was analyzed for participants who developed AMS versus those who did not. Finally, the self-reported variables were considered separately to determine their significance to summit success or the development of AMS. Independent Student's $t$ tests were run for continuous variables, and crosstabs with $\chi^{2}$ analyses were done for dichotomous variables such as acetazolamide use and history of altitude illness. Significance for all analyses was based on $P \leq .05$. All statistical analyses were done using PASW software (version 18.0; IBM, Chicago, IL).

\section{Results}

During the 8 days of data collection, 77 climbers arrived at the hut with the intention of summiting the mountain. Of those 77 climbers, 2 chose not to participate in the study, and 2 were excluded because of communication barriers, leaving 73 volunteers. Twelve of the 73 failed to complete all parts of the data collection, leaving 61 participants for analysis. Of the 61 participants, 13 reported using acetazolamide at some point during the expedition; there were no reports of dexamethasone use. Paired Student's $t$ tests revealed no significant differences in $\mathrm{HR}, \mathrm{SpO}_{2}$, or LLSS for each data collection period between those taking acetazolamide and those who did not. Furthermore, although summit success was slightly greater for those taking the drug $(76.9 \%)$ than those not $(60.4 \%)$, this difference was not significant $(P=.27)$. Thus, acetazolamide users and nonusers were combined for subsequent analyses. Finally, 5 climbers (8.2\%) developed AMS while in the hut before a summit attempt. These 5 were excluded from subsequent analyses, leaving a sample size of 56 (51 men and 5 women). Descriptive statistics for the study sample are summarized in Table 1.

Participants stayed at the hut an average of $16.8 \pm$ 13.1 hours (median, 10.0 hours) before departing for the summit. For those who reached the summit $(n=37)$, the average round trip (hut-summit-hut) time was $13.5 \pm$ 2.1 hours (median, 13.7 hours). Of the participants, 37 $(66.1 \%)$ successfully reached the summit. For those unable to reach the summit, reasons given were perceived AMS in 7 of $19(36.8 \%)$ cases, fatigue in $9(47.4 \%)$ cases, partner failure in $2(10.5 \%)$ cases, and other reasons in $1(5.3 \%)$ case. Thirty-three $(58.9 \%)$ participants self-reported AMS during the ascent. In addition, 24 of these 33 AMS cases $(72.7 \%)$ were severe as they scored $\geq 5$ on the LLSS. Data for $\mathrm{Spo}_{2}$, HR, and LLSS scores for each of the 3 data collections are reported in Table 2 .

The $\mathrm{SpO}_{2}$ measured on arrival at the hut was nearly identical between those who would later experience AMS during the ascent $(86.5 \% \pm 4.2 \%)$ and those who did not $(86.2 \% \pm 3.8 \%)$. There was no significant difference $(P=.82)$ in preascent $\mathrm{SpO}_{2}$ between those who experienced AMS during ascent $\left(\mathrm{SpO}_{2}, 84.3 \% \pm 4.0 \%\right)$ and those who did not $\left(\mathrm{SpO}_{2}, 84.6 \% \pm 3.2 \%\right)$. Figure 1 displays no correlation $(r=-.007)$ between preascent $\mathrm{SpO}_{2}$ measurements and subsequent AMS severity. Similarly, preascent HR was not correlated with subsequent AMS severity $(r=.066)$, and there was no difference $(P=$ .23) between climbers who would later get AMS (89.0 \pm 15.6 beats $\left.\cdot \mathrm{min}^{-1}\right)$ and those who would not $(94.3 \pm 16.2$ beats $\left.\cdot \min ^{-1}\right)$. There was also no significant difference $(P=.44)$ in preascent $\mathrm{SpO}_{2}$ between those who reached the summit $\left(\mathrm{SpO}_{2}, 84.7 \% \pm 3.5 \%\right)$ and those who did not $\left(\mathrm{SpO}_{2}, 83.9 \% \pm 4.0 \%\right)$. However, summiteers had lower resting HRs just before the summit attempt $(88.1 \pm 15.4$ vs $97.3 \pm 15.6$ beats $\left.\cdot \min ^{-1} ; P=.04\right)$ than those who failed to reach the summit.

Figure 2 shows the average $\mathrm{Spo}_{2}$ and HR measurements at each stage of data collection for those who developed AMS and those who did not. The $\mathrm{Spo}_{2}$ was not significantly different between the 2 groups on arrival at the hut $(P=.81)$ or immediately before departing the hut for the summit attempt $(P=.82)$. The $\mathrm{SpO}_{2}$ was, however, significantly different $(P=.05)$ between those who developed AMS during the ascent and those who did not when measured on the climbers' return to the hut. Resting HR gradually increased throughout the study, but the differences between AMS and non-AMS participants were not significant at any time.

The influence of the self-reported variables to AMS development and summit success are outlined in Table 1. Climbers residing at a higher altitude $(1608 \pm 823 \mathrm{~m}$ vs $1128 \pm 920 \mathrm{~m}$ ) had significantly fewer incidences of AMS during the ascent; however, altitude of residence did not correlate with $\mathrm{Spo}_{2}$ for any of the 3 data collections at the hut. Those who spent more time above $3000 \mathrm{~m}$ in the days preceding the ascent were more likely to reach the summit. There was a trend for a higher prevalence of AMS among participants who self-reported a history of altitude illness compared with those who did not (74\% vs 48\%), but this difference did not reach statistical significance $(P=.06)$. Those who experienced AMS and those who did not, as well as summiteers and nonsummiteers, were similar with regard to other self-reported variables (see Table 1). 
Table 1. Mean \pm SD (and range) for self-reported descriptive statistics

\begin{tabular}{|c|c|c|c|c|c|}
\hline \multirow[b]{2}{*}{ Variable } & \multirow{2}{*}{$\frac{\text { Total }}{(N=56)}$} & \multicolumn{2}{|c|}{$A M S$} & \multicolumn{2}{|c|}{ Summit } \\
\hline & & Yes $(n=33)$ & No $(n=23)$ & Yes $(n=37)$ & No $(n=19)$ \\
\hline Age (years) & $35.0 \pm 10.1(18-61)$ & $33.7 \pm 10.0(21-60)$ & $37.0 \pm 10.1(18-61)$ & $34.0 \pm 8.9(20-56)$ & $37.0 \pm 12.0(18-61)$ \\
\hline Height (cm) & $175.6 \pm 7.2(148-190)$ & $176.1 \pm 6.2(163-188)$ & $174.8 \pm 8.5(148-190)$ & $176.4 \pm 7.5(148-190)$ & $174.0 \pm 6.5(164-188)$ \\
\hline Weight (kg) & $75.1 \pm 11.3(45-100)$ & $74.2 \pm 10.1(52-90)$ & $76.4 \pm 12.9(45-100)$ & $76.9 \pm 10.9(45-100)$ & $71.5 \pm 11.4(52-90)$ \\
\hline $\operatorname{BMI}\left(\mathrm{kg} \cdot \mathrm{m}^{-2}\right)^{a}$ & $24.3 \pm 3.3(18-33)$ & $23.9 \pm 3.0(18-31)$ & $24.9 \pm 3.6(19-33)$ & $24.7 \pm 3.0(20-33)$ & $23.7 \pm 3.9(18-31)$ \\
\hline Residence (m) & $1325 \pm 906(0-3000)$ & $1128 \pm 920(0-2500)$ & $1608 \pm 823^{c}(0-3000)$ & $1077 \pm 939(0-3000)$ & $1807 \pm 610^{c}(0-2400)$ \\
\hline Ascents $>3000 \mathrm{~m}^{b}$ & $1.3 \pm 1.8(0-10)$ & $1.3 \pm 2.0(0-10)$ & $1.4 \pm 1.6(0-5)$ & $1.7 \pm 2.0(0-10)$ & $0.6 \pm 1.3^{c}(0-4)$ \\
\hline Time $(\mathrm{h})>3000 \mathrm{~m}^{b}$ & $22.9 \pm 40.9(0-240)$ & $28.1 \pm 48.0(0-240)$ & $15.5 \pm 27.0(0-85)$ & $31.9 \pm 46.8(0-240)$ & $5.4 \pm 15.5^{c}(0-65)$ \\
\hline Highest ascent (m) & $5531 \pm 981(3779-8850)$ & $5186 \pm 762(3779-6964)$ & $6026 \pm 1060^{c}(4400-8850)$ & $5559 \pm 968(3939-8082)$ & $5476 \pm 1030(3779-8850)$ \\
\hline $\begin{array}{l}\text { Training time } \\
\left(\mathrm{h} \cdot \mathrm{wk}^{-1}\right)\end{array}$ & $8.9 \pm 6.9(0-25)$ & $8.9 \pm 7.0(0-24)$ & $8.6 \pm 6.9(0-25)$ & $9.7 \pm 6.9(0-25)$ & $7.1 \pm 6.8(0-20)$ \\
\hline
\end{tabular}

\footnotetext{
${ }^{a}$ Body mass index (BMI) was calculated from the self-reported weights and heights.

${ }^{b}$ In the 10 days previous to this study; $P<.05$.
}

${ }^{c}$ Indicates significant difference from those in respective Yes group. 
Table 2. Heart rates, arterial oxygen saturations, and Lake Louise Self-Assessment Scale scores for the 3 data collection periods $(N=56)$

\begin{tabular}{|c|c|c|c|c|c|c|}
\hline \multirow[b]{2}{*}{ Variable } & \multicolumn{2}{|c|}{ On arrival at hut } & \multicolumn{2}{|c|}{$\begin{array}{c}\text { At departure for summit } \\
\text { attempt }\end{array}$} & \multicolumn{2}{|c|}{$\begin{array}{c}\text { Return from summit } \\
\text { attempt }\end{array}$} \\
\hline & Range & Mean $\pm S D$ & Range & Mean $\pm S D$ & Range & Mean $\pm S D$ \\
\hline $\mathrm{HR}$ (beats $\cdot \min ^{-1}$ ) & $53-125$ & $83.0 \pm 15.5$ & $57-124$ & $91.2 \pm 15.9$ & $78-129$ & $103.7 \pm 12.6$ \\
\hline Diamox use $(n=12)$ & $63-103$ & $85.1 \pm 12.7$ & $57-124$ & $94.0 \pm 20.7$ & $85-129$ & $108.3 \pm 14.1$ \\
\hline No Diamox $(n=44)$ & $53-125$ & $82.4 \pm 16.3$ & $58-118$ & $90.4 \pm 14.5$ & $78-129$ & $102.4 \pm 12.0$ \\
\hline $\mathrm{SpO}_{2}(\%)$ & $74-94$ & $86.4 \pm 4.0$ & $72-90$ & $84.4 \pm 3.7$ & $75-93$ & $84.3 \pm 5.3$ \\
\hline Diamox use $(n=12)$ & $83-91$ & $86.2 \pm 2.7$ & $79-90$ & $85.4 \pm 3.3$ & $76-87$ & $82.6 \pm 4.3$ \\
\hline No Diamox $(n=44)$ & 74-94 & $86.4 \pm 4.3$ & $72-90$ & $84.2 \pm 3.8$ & $75-93$ & $85.0 \pm 5.3$ \\
\hline LLSS score & $0-3$ & $0.7 \pm 0.9$ & $0-5$ & $1.4 \pm 1.3$ & $0-12$ & $4.8 \pm 2.9$ \\
\hline Diamox use $(n=12)$ & $0-2$ & $0.8 \pm 0.8$ & $0-4$ & $1.3 \pm 1.2$ & $0-9$ & $4.8 \pm 2.9$ \\
\hline No Diamox $(n=44)$ & $0-3$ & $0.7 \pm 0.9$ & $0-5$ & $1.5 \pm 1.3$ & $0-12$ & $4.9 \pm 3.0$ \\
\hline
\end{tabular}

Diamox, acetazolamide; HR, Heart rates; $\mathrm{SpO}_{2}$, arterial oxygen saturations; LLSS, Lake Louise Self-Assessment Scale.

\section{Discussion}

\section{PULSE OXIMETRY AND AMS}

Our study was similar to that of Roach et $\mathrm{al}^{8}$ in that both investigative teams measured the $\mathrm{Spo}_{2}$ of mountaineers at similar altitudes and obtained self-reported AMS symptoms from the climbers on their descent. Roach et $\mathrm{al}^{8}$ reported that a low $\mathrm{Spo}_{2}$ was significantly correlated with the development of AMS on Denali and concluded that pulse oximetry could be used to predict subsequent AMS; we found no such relationship. The key design difference between the 2 studies was the duration of time that climbers spent at high altitude and the time span between $\mathrm{SpO}_{2}$ sampling and retrospective AMS query. Although Pico de Orizaba and Denali differ in height by

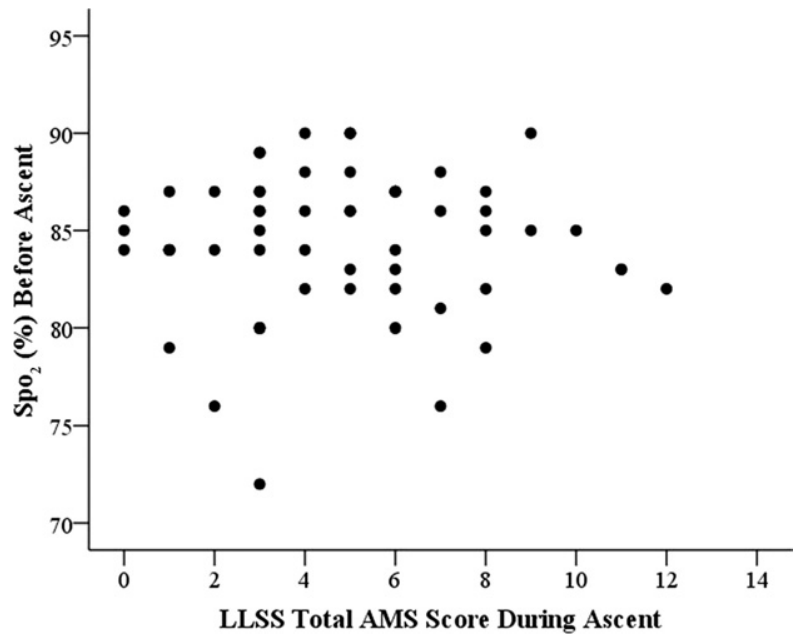

Figure 1. Relationship between arterial oxygen saturation $\left(\mathrm{SpO}_{2}\right)$ before the summit attempt and the total Lake Louise Self-Assessment Scale (LLSS) score for acute mountain sickness (AMS) during the summit attempt $(r=-0.007)$. only $554 \mathrm{~m}$, the style and rate in which the mountains are climbed differs greatly. Our Pico de Orizaba participants typically completed the climb and data collection within 24 hours, climbing alpine style without the use of higher camps. In contrast, an additional camp is typically placed above the point at which Roach et $\mathrm{al}^{8}$ collected their data on Denali. These researchers noted that their subjects had been at $4200 \mathrm{~m}$ for several days both before and after their initial $\mathrm{SpO}_{2}$ measurement and above $4200 \mathrm{~m}$ for an average of 3 days before being retested. In this span of time between tests, factors other than the initial $\mathrm{SpO}_{2}$ measurement could have influenced the development of AMS. For example, researchers have suggested that exercise $^{11}$ and cold exposure ${ }^{12}$ can exacerbate AMS.

Another methodological difference between our study and that of Roach et $\mathrm{al}^{8}$ is that they excluded climbers presenting with AMS or taking acetazolamide, and we did not. It is well known that acetazolamide can decrease the symptoms and severity of AMS, thereby creating a potential confounding factor in the study. However, as there were no differences in the variables of interest between climbers taking acetazolamide and those not on the drug (see Table 2), we included them in the analyses. Other researchers have also reported that acetazolamide had a negligible effect on the incidence of AMS, ${ }^{12,13}$ particularly during steep or rapid ascents. ${ }^{14-16}$

In agreement with Roach et $\mathrm{al}^{8}$ and in contrast to our findings, other researchers have also suggested that a low $\mathrm{SpO}_{2}$ value can be predictive of subsequent AMS. In a recent study that used data from 8 different expeditions, Karinen et $\mathrm{al}^{7}$ found that the $\mathrm{Spo}_{2}$ values measured at $3500 \mathrm{~m}$ and $4300 \mathrm{~m}$ were predictive of impending AMS at higher altitudes. Significant relationships between $\mathrm{SpO}_{2}$ and AMS have also been reported during mountaineering expeditions to Muztagh $\mathrm{Ata}^{17}$ and Broad 


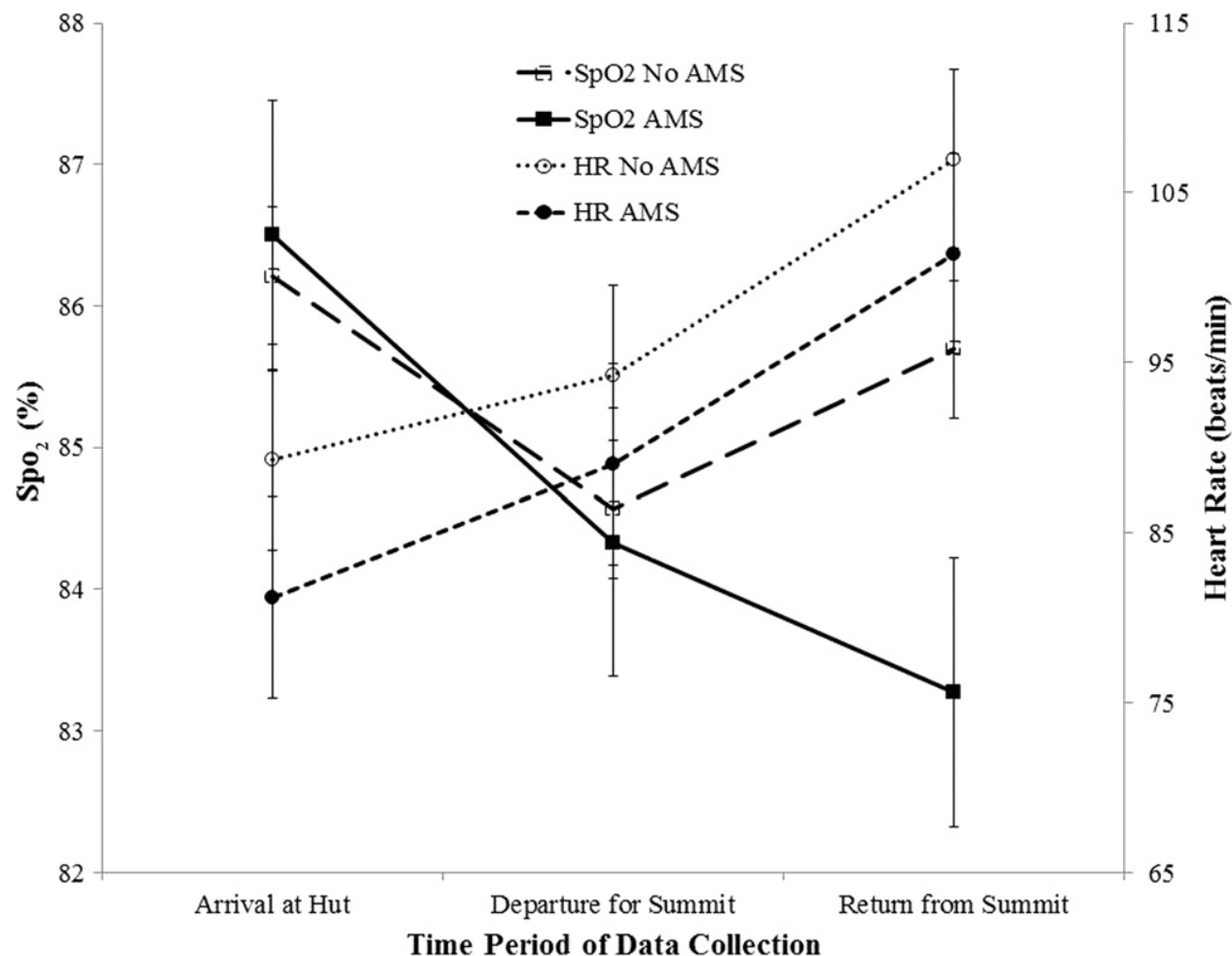

Figure 2. Mean \pm SEM arterial oxygen saturation $\left(\mathrm{SpO}_{2}\right)$ and heart rate (HR) at 3 different times in participants who eventually developed acute mountain sickness (AMS) versus those who did not.

Peak, ${ }^{18}$ and treks in the Khumbu ${ }^{19}$ and Langtang ${ }^{20}$ regions of Nepal. Additionally, several researchers have examined the ability of postexercise $\mathrm{Spo}_{2}$ or the magnitude of change between resting and postexercise $\mathrm{SpO}_{2}$ to predict AMS with varying success. ${ }^{15,21,22}$ The common thread among all of these studies is that $\mathrm{Spo}_{2}$ was being used to predict AMS that might occur after prolonged (several days) hypoxic exposure. In contrast, studies that have simultaneously measured $\mathrm{SpO}_{2}$ and administered the LLSS after rapid (approximately 1 day) ascent to $2940 \mathrm{~m}$ in the Austrian Alps, ${ }^{23}$ to $3080 \mathrm{~m}$ on Mt Rainier, ${ }^{5}$ or to the $4419-\mathrm{m}$ summit of Mt Whitney ${ }^{6}$ have found no relationship between $\mathrm{Spo}_{2}$ and AMS. These comparisons suggest that a longer duration of hypoxic exposure ( $>1$ day) may be needed to find a significant relationship between $\mathrm{SpO}_{2}$ and AMS.

Of particular interest are the 5 climbers who were excluded from the analyses because they developed AMS while in the hut. Despite their condition and against the advice of the researchers, all 5 elected to make an attempt on the summit. Only 2 of the 5 reached the summit, and the magnitude of AMS for all 5 progressed to severe AMS (LLSS $\geq 5$ ) during the ascent. Their $\mathrm{SpO}_{2}$ values on arrival at the hut and just before their attempts were not significantly different from those of the other climbers.
It is interesting to note that the difference in $\mathrm{SpO}_{2}$ between those who developed AMS and those who did not in the present study was not significant at the outset on arrival at $4260 \mathrm{~m}$ or before their departure for the summit attempt after an additional 10 hours at this altitude; however, those who later developed AMS had a significantly lower $\mathrm{Spo}_{2}$ on return from the summit after an additional 13 hours at high altitude (see Figure 2). We are unaware of other published studies in which this latent drop in $\mathrm{SpO}_{2}$ among those afflicted with AMS occurs. We can only speculate that AMS alters gas exchange, ${ }^{24-26}$ but further research is needed to validate lowered $\mathrm{SpO}_{2}$ values in AMS-afflicted climbers compared with AMS-free climbers after descent and to identify the mechanism behind this phenomenon.

\section{PULSE OXIMETRY AND SUMMIT SUCCESS}

Researchers have identified a variety of factors that are predictive of success during mountaineering expeditions, including age, ascent rate, training time, and previous high altitude experience. ${ }^{17,27-31}$ Arterial oxygen saturation has rarely been considered in these investigations. Recently, Lazio et $\mathrm{al}^{31}$ reported significantly higher resting and postexercise $\mathrm{SpO}_{2}$ values for successful vs unsuccessful climbers on Mt Aconcagua. Tannheimer et $\mathrm{al}^{18}$ reported a 
significant correlation between $\mathrm{Spo}_{2}$ measured at base camp and subsequent high altitude performance for climbers on a Broad Peak $(8047 \mathrm{~m})$ expedition. They noted that the 4 climbers with the highest $\mathrm{Spo}_{2}$ at base camp reached the highest altitudes during the expedition. These results are in contrast to our findings of no difference in preascent $\mathrm{SpO}_{2}$ between those who reached the summit and those who did not. Results from other researchers on this topic are equivocal. When the $\mathrm{Spo}_{2}$ of acetazolamide-using trekkers was measured at $4700 \mathrm{~m}$ during a 4-day ascent of Mt Kilimanjaro $(5895 \mathrm{~m})$, it was significantly higher in those who would go on to reach the summit than those who failed; however, the $\mathrm{Spo}_{2}$ was not significantly different between summiteers and nonsummiteers who were not taking the drug or who had a 5-day ascent profile. ${ }^{32}$ Bloch et $\mathrm{al}^{17}$ noted a weak trend between $\mathrm{Spo}_{2}$ and climbing success on Muztagh Ata $(7546 \mathrm{~m})$. However, close inspection of their data reveals that climbers in the highest quartile for $\mathrm{SpO}_{2}$ measured at base camp had a lower success rate (75\%) than those in 2 lower quartiles (78\% and 80\%).

Summiteers had lower HRs than the unsuccessful climbers just before their summit attempts. The lower resting HR for summiteers could be related to a variety of factors including superior fitness and less anxiety, both of which would likely be beneficial for a rapid ascent. Few researchers have considered the influence of resting HR on summit success. Tsianos et $\mathrm{al}^{29}$ reported a resting HR that was, on average, 9 beats $\cdot \min ^{-1}$ lower for those who reached the summit of Mont Blanc compared with those who did not, but this difference was not significant. Additionally, resting HR was not a significant predictor of reaching the summits of Mt Kilimanjaro ${ }^{32}$ or Mt Aconcagua. ${ }^{31}$ Finally, it is important to note that of the 37 Pico de Orizaba summiteers, 14 (38\%) had an LLSS of $\geq 5$. This is not surprising, as it is well supported in the literature that the presence of AMS is not related to summit success. ${ }^{14,28-30}$

\section{LIMITATIONS}

As with all studies of AMS, it was assumed that the climbers were giving truthful responses regarding their symptoms and severity. Many of the study participants were Mexican men. "Machismo," the cultural concept of manliness, is known to influence how Mexican men perceive health and illness, ${ }^{33}$ and this may have been a factor in their responses to the LLSS. Also, the researchers did not ascend with the climbers; thus, the first 2 data collections took place in real-time, but the third was administered retrospectively after the participants returned from their summit attempts. The accuracy of recalling symptoms and severity is likely less than when assessed in the moment. Finally, standard protocol $^{34}$ was followed to maximize the accuracy of the pulse oximetry reading. However, considerable fluctuations in $\mathrm{SpO}_{2}$ from finger pulse oximetry are common, and researchers must select the most frequent value ${ }^{34}$; this is a subjective judgment that can lead to error.

\section{CONCLUSIONS AND IMPLICATIONS}

Arterial oxygen saturation as measured by finger pulse oximetry was neither predictive of AMS nor summit success during a rapid ascent to $5640 \mathrm{~m}$; a low HR at $4260 \mathrm{~m}$, however, was advantageous for reaching the summit. The climbers in this study achieved altitude quickly by arriving at a high base camp by vehicle and then attempting to reach the summit in less than a day. This strategy is commonly used for climbing attempts on many mountains around the world including "14ers" (14 000-foot or 4267-m peaks) in the United States, classic climbs in the European Alps, and even some Andean volcanoes of nearly $6000 \mathrm{~m}$. Although it would be ideal to have some objective and quantifiable predictor of who is most likely to succeed or suffer from altitude illness on these rapid ascents, $\mathrm{SpO}_{2}$ does not appear to be a valid predictor in this setting. It is important for mountaineers, guides, and the medical staff on climbing parties to recognize the limitations of finger pulse oximetry. In a recent review of pulse oximetry at high altitude, Luks and Swenson ${ }^{34}$ state that "there is a significant potential for misidentification" when using $\mathrm{Spo}_{2}$ to predict AMS and summit success, and these authors place this practice into question. We concur, and our data support this position that relying on pulse oximetry could lead to inappropriate clinical or climbing decisions, especially when applied to rapid ascents. There is some evidence that suggests $\mathrm{SpO}_{2}$ may be predictive of AMS and possibly climbing performance on longer expeditions, but more research is needed to identify the magnitude (time exposure and altitude) of hypoxia needed for valid prediction.

\section{Acknowledgments}

We thank the climbers who took the time to participate in this study, and we are grateful to the following for providing financial support for the data collection: Wilderness Medical Society (Herbert N. Hultgren Award), American Alpine Club (standard research grant), and Mazamas (standard research grant).

\section{References}

1. Roach RC, Bärtsch P, Oelz O, Hackett PH. The Lake Louise acute mountain sickness scoring system. In: Sutton JR, Houston CS, Coates G, eds. Hypoxia and Molecular Medicine. Burlington, VT: Queen City Printers; 1993: 272-274. 
2. Hackett PH, Roach RC. High-altitude illness. N Engl J Med. 2001;345:107-114.

3. Sampson JB, Cymerman A, Burse RL, Maher JT, Rock PB. Procedures for the measurement of acute mountain sickness. Aviat Space Environ Med. 1983;54(12 Pt 1): 1063-1073.

4. Wagner DR, Parker D, Tatsugawa K, Young TA. Reliability and utility of a visual analog scale for the assessment of acute mountain sickness. High Alt Med Biol. 2007;8: 27-31.

5. O'Connor T, Dubowitz G, Bickler PE. Pulse oximetry in the diagnosis of acute mountain sickness. High Alt Med Biol. 2004;5:341-348.

6. Wagner DR, Fargo JD, Parker D, Tatsugawa K, Young TA. Variables contributing to acute mountain sickness on the summit of Mt Whitney. Wilderness Environ Med. 2006;17:221-228.

7. Karinen HM, Peltonen JE, Kähönen M, Tikkanen HO. Prediction of acute mountain sickness by monitoring arterial oxygen saturation during ascent. High Alt Med Biol. 2010;11:325-332.

8. Roach RC, Greene ER, Schoene RB, Hackett PH. Arterial oxygen saturation for prediction of acute mountain sickness. Aviat Space Environ Med. 1998;69:1182-1185.

9. Burtscher M, Szubski C, Faulhaber M. Prediction of the susceptibility to AMS in simulated altitude. Sleep Breath. 2008;12:103-108.

10. West JB, Schoene RB, Milledge JS. High Altitude Medicine and Physiology. 4th ed. London: Hodder Arnold; 2007.

11. Roach RC, Maes D, Sandoval D, et al. Exercise exacerbates acute mountain sickness at simulated high altitude. J Appl Physiol. 2000;88:581-585.

12. Anderson PJ, Miller AD, O'Malley KA, et al. Incidence and symptoms of high altitude illness in South Pole workers: Antarctic Study of Altitude Physiology (ASAP). Clin Med Insights Circ Respir Pulm Med. 2011;5:27-35.

13. Croughs M, Van Gompel A, Van den Ende J. Acute mountain sickness in travelers who consulted a pre-travel clinic. J Travel Med. 2011;18:337-343.

14. Jackson SJ, Varley J, Sellers C, et al. Incidence and predictors of acute mountain sickness among trekkers on Mount Kilimanjaro. High Alt Med Biol. 2010;11:217-222.

15. Karinen H, Peltonen J, Tikkanen H. Prevalence of acute mountain sickness among Finnish trekkers on Mount Kilimanjaro, Tanzania: an observational study. High Alt Med Biol. 2008;9:301-306.

16. Kayser B, Hulsebosch R, Bosch F. Low-dose acetylsalicylic acid analog and acetazolamide for prevention of acute mountain sickness. High Alt Med Biol. 2008;9:15-23.

17. Bloch KE, Turk AJ, Maggiorini M, et al. Effect of ascent profile on acute mountain sickness and success at Muztagh Ata, 7546 m. High Alt Med Biol. 2009;10:25-32.

18. Tannheimer M, Thomas A, Gerngross H. Oxygen saturation course and altitude symptomatology during an expedition to Broad Peak (8047 m). Int J Sports Med. 2002;23: $329-335$
19. Basnyat B, Lemaster J, Litch JA. Everest or bust: a cross sectional, epidemiological study of acute mountain sickness at 4243 meters in the Himalayas. Aviat Space Environ Med. 1999;70:867-873.

20. Koehle MS, Guenette JA, Warburton DER. Oximetry, heart rate variability, and the diagnosis of mild-tomoderate acute mountain sickness. Eur J Emerg Med. 2010;17:119-122.

21. Hooper TJ, Levett DZH, Mellor AJ, Grocott MPW. Resting and exercising cardiorespiratory variables and acute mountain sickness. J R Nav Med Serv. 2010;96:6-12.

22. Tannheimer M, Albertini N, Ulmer HV, Thomas A, Engelhardt M, Schmidt R. Testing individual risk of acute mountain sickness at greater altitudes. Mil Med. 2009;174: 363-369.

23. Roeggla G, Roeggla M, Podolsky A, Wagner A, Laggner AN. How can acute mountain sickness be quantified at moderate altitude? J R Soc Med. 1996;89:141-143.

24. Bärtsch P, Swenson ER, Paul A, Jülg B, Hohenhaus E. Hypoxic ventilatory response, ventilation, gas exchange, and fluid balance in acute mountain sickness. High Alt Med Biol. 2002;3:361-376.

25. Loeppky JA, Icenogle MV, Charlton GA, et al. Hypoxemia and acute mountain sickness: which comes first? High Alt Med Biol. 2008;9:271-279.

26. Sutton JR, Bryan AC, Gray GW, et al. Pulmonary gas exchange in acute mountain sickness. Aviat Space Environ Med. 1976;47:1032-1037.

27. McIntosh SE, McDevitt M, Rodway GW, Dow J, Grissom CK. Demographic, geographic, and expedition determinants of reaching the summit of Denali. High Alt Med Biol. 2010;11:223-229.

28. Pesce C, Leal C, Pinto H, et al. Determinants of acute mountain sickness and success on Mount Aconcagua (6962 m). High Alt Med Biol. 2005;6:158-166.

29. Tsianos G, Woolrich-Burt L, Aitchison T, et al. Factors affecting a climber's ability to ascend Mont Blanc. Eur J Appl Physiol. 2006;96:32-36.

30. Wagner DR, D'Zatko K, Tatsugawa K, et al. Mt. Whitney: determinants of summit success and acute mountain sickness. Med Sci Sport Exerc. 2008;40:1820-1827.

31. Lazio MP, Van Roo JD, Pesce C, Malik S, Courtney DM. Postexercise peripheral oxygen saturation after completion of the 6-minute walk test predicts successfully reaching the summit of Aconcagua. Wilderness Environ Med. 2010;21: 309-317.

32. Davies AJ, Kalson NS, Stokes S, et al. Determinants of summiting success and acute mountain sickness on $\mathrm{Mt}$ Kilimanjaro (5895 m). Wilderness Environ Med. 2009;20: 311-317.

33. Sobralske M. Machismo sustains health and illness beliefs of Mexican American men. J Am Acad Nurse Pract. 2006; 18:348-350.

34. Luks AM, Swenson ER. Pulse oximetry at high altitude. High Alt Med Biol. 2011;12:109-119. 